\title{
AS CRIANÇAS EM CENA, CONTEXTOS E IDENTIDADES: REFLEXÕES SOBRE O CONTRIBUTO DE PESQUISADORES VINCULADOS AO "PROJECTO DE INVESTIGAÇÃO SOBRE A INFÂNCIA EM PORTUGAL"***
}

\author{
Josemir Almeida Barros* \\ Nilce Vieira Campos Ferreira**
}

\begin{abstract}
RESUMO
Apresentamos reflexões sobre pesquisas desenvolvidas no âmbito do "Projecto de investigação sobre a infância em Portugal" (PiiP) realizado de 1997 a 1999. Esse estudo, em Portugal, abordou a redefinição do campo da infância e dos médias por meio de levantamento bibliográfico realizado no período de 1974 a 1998. Nessa concepção, discorremos a respeito da história da infância, a partir da visão desses investigadores, ponderando que com o advento da sociedade industrial as crianças assumiram um novo lugar como cidadãos em formação, o que incluiu uma relação com o trabalho na sociedade capitalista e suas múltiplas implicações. A indagação que trazemos é a seguinte: a circulação de temáticas sobre as crianças acarretou melhores condições sociais para esse público?
\end{abstract}

Palavras-chave: Crianças. História da infância. História da educação. Escola. Políticas públicas.

\begin{abstract}
We brought reflections on research developed in the scope of "Projecto de investigação sobre infância em Portugal (PiiP) (Project of childhood investigation in Portugal), made from 1997 to 1999. This study in

\footnotetext{
* Doutor em Educação pela Universidade Federal de Uberlândia (bolsista FAPEMIG), Uberlândia-MG, Brasil. Professor da Faculdade de Educação da Universidade do Estado de Minas Gerais, Belo Horizonte-MG. E-mail: josemirbh@yahoo.com.br

** Doutora em Educação pela Universidade Federal de Uberlândia, Uberlândia-MG, Brasil. Professora do Instituto de Educação da Universidade Federal do Mato Grosso, Cuiabá MT. E-mail: nilcevieiraura@hotmail.com

${ }^{* * *}$ Esse artigo resulta das pesquisas realizadas no doutorado intercalar de Josemir Almeida Barros na Universidade do Minho em Braga, Portugal e de Nilce V.C. Ferreira no Instituo de Educação da Universidade de Lisboa, Portugal. Ambos foram financiados pela CAPES.
} 
Portugal is about the redefinition on the childhood field and the medias through bibliographical research made between 1974 and 1998. Using this conception, we discuss from the point of view of these investigators about these little human beings, pondering that with the event of the industrial society children have assumed a new role as citizens in development, included in the labor relation in the capitalist society and its various implications. The question which has arisen is the following one: the widespread circulation on themes about children has evolved into better social conditions to this public?

Keywords: Children. History of childhood. History of Education. School. Public politics.

O centro dos debates ou temática que compõe esse texto são as crianças, seres em contextos e com identidades marcadas por distintas histórias, concepções e entendimentos. Notamos que essas discussões emergiram porque tanto no cenário nacional, em Portugal, como no internacional, as agendas políticas se voltaram para as crianças e suas problemáticas vinculadas à infância.

As reflexões que trazemos, dessa forma, constituem contributos a partir da obra As crianças: contextos e identidades publicada pelo Centro de Estudos da Criança da Universidade do Minho na cidade de Braga, Região Norte de Portugal. Essa obra é parte dos estudos e das pesquisas de professores vinculados ao Projeto de investigação sobre a infância em Portugal (PiiP) ${ }^{1}$ desenvolvido no período de 1997 a 1999.

No campo dos médias, muitas abordagens sobre as crianças e a infância também foram intensificadas em programas televisivos. A esse respeito, enfatizamos que em Portugal aparecem diversos indicadores sobre as condições da vida das crianças e sua entrada no cotidiano (SARMENTO; PINTO, 1997). O ingresso precoce das crianças no universo do trabalho entre outros fatores parece ter despertado o interesse dos médias.

\footnotetext{
1 O PiiP foi "promovido no âmbito do Instituto de Estudos da Criança da Universidade do Minho e apoiado pela Fundação Calouste Gulbenkian e pelo Centro de Estudos da Criança, o seu conteúdo é constituído pelo levantamento bibliográfico da produção científica portuguesa sobre a infância e as crianças, realizada entre 1974 e o primeiro semestre de 1998." Cf. PINTO; SARMENTO, 1999. p. 10. Esse artigo emergiu da obra: PINTO; SARMENTO, 1997.
} 
Com a intensificação dos debates científicos por meio de maior número de pesquisas fora dos limites tradicionais do campo médico e da Psicologia do Desenvolvimento problemáticas associadas à infância também se fizeram presentes nas agendas políticas.

A temática da infância, dessa forma, destacou-se em discursos e ações políticas das autoridades públicas, mas mesmo assim isso não significou o amparo total às crianças e muitos são os conflitos e problemas que as envolvem na contemporaneidade. Elas continuaram sendo as "principais vítimas dos conflitos contemporâneos, da 'guerra das cidades' da Bosnia-Herzgovina [...] intensifica-se em certas regiões do globo a prostituição infantil [...] o trabalho infantil; $[. .$.$] 'meninos de rua' em$ algumas cidades [...]"(SARMENTO; PINTO, 1997, p. 12).

Os estudos da infância perpassaram e perpassam o fenômeno social, sendo o conceito de infância uma construção social(SARMENTO; PINTO, 1997) e, portanto, histórico, surgindo a partir de diversas preocupações. Entre elas, destacamos a disciplina e a racionalidade dos costumes. Nos aspectos demográficos, contudo, o número de crianças vem diminuindo em diversos países europeus, o que as levou a se tornarem foco de ações políticas e a serem consideradas por diversas instituições, implicando a perspectiva de uma nova cultura.

A cultura vista como um sistema simbólico e o contexto social como um conjunto de relações e interações entre indivíduos alterou significativamente o olhar sobre a infância (FERREIRA; BEGNAMI, 2009). Apesar de a Convenção dos Direitos das Crianças estabelecer direitos necessários, as desigualdades e a descriminação contra as próprias crianças aumentaram. Por um lado, as crianças passaram a ocupar um lugar de destaque e a desempenhar papeis mais visíveis em nossa sociedade, por outro não tiveram as práticas de seus direitos sociais assegurados a contento.

[...] o que está em causa na controvérsia sobre a natureza dos direitos das crianças é o juízo sobre a infância como categoria social construída por actores sociais de pleno direito, ainda que com características específicas, considerando a sua idade, ou, ao invés, como destinatários apenas de cuidados sociais específicos. A primeira concepção implica uma interpretação holística dos direitos, no quadro da qual - ao 
contrário da segunda - não apenas é erróneo, como pode ser perverso, o centramento dos direitos da criança na proteç̧ão e (mesmo) na provisão de meios essenciais de crescimento, sem que se reconheça às crianças o estatuto de actores sociais e à partilha da decisão nos seus mundos de vida (SARMENTO; PINTO, 1997, p. 20).

Ao considerarmos as crianças na condição de atores sociais detentores de direitos destacamos também a constituição de suas representações e crenças, ou seja, sistemas culturais. Dessa forma, julgamos importante a "focagem nas dimensões sociais da infância, isto é, no conjunto de processos sociais, mediante os quais a infância emerge com realidade social, realidade essa que também produz, em certa medida, a própria sociedade." (PINTO, 1997, p. 34).

Nesse aspecto, Pinto (1997) discorre em uma abordagem histórica sobre a infância apoiando-se no trabalho de Philippe Ariès (2006), na qual a ideia moderna de infância com fase autônoma em relação à vida adulta se tornou consistente a partir de fins do século XVII, especificamente no XVIII, nos setores da aristocracia e na burguesia. Além disso, na Idade Média, as crianças eram representadas como adultos em miniatura e "quanto mais recuamos nessa história, mais probabilidade teremos, segundo ele, de nos confrontarmos com a morte, o abandono, a violência, o terror e o abuso sexual sobre as crianças" (PINTO, 1997, p. 38).

\section{A construção social das ideias sobre a infância}

A nova realidade, estabelecida concomitantemente à lenta construção social da "evolução" das ideias sobre a infância, aponta para novas mentalidades difundidas a partir do Renascimento e desde então. Fundamentado nas investigações no campo da História, Ariès utilizou fontes diversificadas como arte religiosa e profana, manuscritos e registros demográficos entre outros. Junto a isso, os estudos das ideias de pensadores e filósofos já conhecidos por nós a exemplo de John Locke (1632-1704) (2012) e Jean Jacques Rousseau (1712-1778) (2004) contribuíram para esse processo de constituição do campo social da infância. Em Emílio, Rousseau inferiu que o adulto deveria proporcionar uma orientação a mais reduzida 
possivel. Locke contribuiu com a teoria da tabula rasa, segundo a qual o ser humano recém-nascido seria uma espécie de cera maleável. Apesar das diferentes abordagens, houve o reconhecimento do caráter decisivo da atenção e da intervenção dos adultos no processo de formação das crianças.

A intensificação e aprofundamento do sentido de infância despertou atenção dos pedagogos e dos fundadores da psicologia, entre eles destacaram-se Sigmund Freud e Georg Herbert Mead.

Para Freud, o mundo infantil abrange inúmeros impulsos e a criança está longe de ser uma tábula rasa como anunciava Locke.

Relativamente ao mundo infantil, Freud mostra que, ao contrário do que sustentava Locke, a criança está longe de poder ser considerada uma tabula rasa. Pelo contrário: para o fundador da Psicanálise, ela está dotada de um aparelho psíquico, de impulsos instintivos e de capacidade de enfrentar os obstáculos que se lhe deparam (ansiedade, separação etc.). Freud mostra igualmente como o conflito edipiano e, sobretudo, a sua resolução, constitui uma condição importante para a abertura da criança ao mundo social (PINTO, 1997, p. 42).

Geoge Herbert Mead, filósofo norteamericano, considerado o fundador do interacionismo simbólico na área das ciências sociais, trouxe à criança o sentido do eu self e do outro. Sobre isso. Pinto destacou que:

Para este pensador, o jogo infantil, entendido no sentido de representação de papeis (ou brincar ao faz de conta), constitui um passo essencial no processo de construção da auto-consciência da criança. Trata-se de uma actividade social que pressupõe um certo domínio da linguagem (palavra, gestos, acções) e um certo contacto com o mundo dos adultos sobretudo dos pais. Ao brincar com uma boneca como se esta fosse a sua filha, a criança, fazendo de conta que é um outro (a mãe ou o pai, por exemplo), entra no mundo (e faz a experiência) desse outro (PINTO, 1997, p. 42-43).

O autor estabeleceu duas consequências para o desenvolvimento infantil: a primeira instituiu a experiência de alteridade, do mundo exterior. A segunda relacionou-se à anterior, ou seja, ao perpetrar a experiência do 
outro a criança se vê em si mesma, torna-se um self. Apesar de todo esse debate frente à temática das crianças, o conceito de infância não se tornou homogêneo e longe se encontra de ser uma categoria universal.

Nas sociedades contemporâneas defende-se que a diluição da infância e da adultez por intermédio dos meios de comunicação é um fenômeno a ser melhor estudado. Segundo Postman (1999), existe hoje o desaparecimento da infância. Essa é de fato uma visão negativa. $\mathrm{O}$ autor culpabiliza os meios de comunicação de massa por esse fato. Inferimos que a ideia de desaparecimento está atrelada à perspectiva de não atendimento dos direitos das crianças.

[...] a propósito do debate sobre os direitos da criança, duas posições extremadas e aparentemente inconciliáveis. Uma que considera a criança um ser carente, não autônomo, em devir, que se torna adulto mediante a interacção com o adulto. Outra que parte da assunção de que as crianças são actores sociais, dotados de competências, capazes de um certo limiar de iniciativa perante as circunstâncias em que vivem. Na primeira acepção, a infância é vista predominantemente como objeto dos projectos e iniciativas dos adultos e merecedora de proteção e educação. Na segunda, ela é entendida como possuidora de um certo grau de autonomia (PINTO, 1997, p. 64).

O excerto trouxe para debate os entendimentos sobre crianças que obviamente surgiram vinculados ao grau de consciência. Nessa perspectiva, as crianças são compreendidas como construtoras de seus mundos sociais. Segundo Pinto (1997), grande parte das propostas que se constituem enquanto construtoras de uma sociologia da infância são teorias e metodologias de inspiração fenomenológica, interacionismo simbólico e a etnometodologia. Concordamos que a infância deve ser entendida como uma construção social, não natural nem universal, mas apresentando-se em suas especificidades de acordo com as cenas, os contextos e as identidades nas quais estão imersas.

Nessa compreensão de questões emergentes sobre a infância, apontamos que a possível pulverização de pesquisas de diversas áreas pode ampliar a discussão. Dessa forma, a Sociologia, a Antropologia, a História, a Psicologia a Semiótica entre outras contribuem alargando o viés dos estudos. $\mathrm{O}$ que sugere possibilidades de diálogos interdisciplinares 
entre diversas áreas do conhecimento das ciências sociais e uma possível colaboração para a construção de saídas mais adequadas às problemáticas colocadas para a infância. Ou seja, isso nos remete para a falta de políticas apropriadas e, concomitantemente, a um sistema de ensino tradicional que pouco valora ações e pensamentos da criança.

Pensamos, aliás, que não apenas a sociologia, mais igualmente outras ciências humanas e sociais podem dar um contributo importante para o estudo da dimensão social da infância, como é o caso da Antropologia, da História, da Semiótica, da Psicologia Social e do Desenvolvimento, etc. Tal pluralidade de focagens constitui-se como uma condição essencial para um melhor conhecimento e valorização do lugar da infância na sociedade (PINTO, 1997, p. 70).

Constatamos que em muitos casos essa diversificação gerou maior circulação de temáticas vinculadas às dimensões sociais da infância. Necessariamente, contudo, suas problemáticas não foram solucionadas e ainda se fazem presentes os vácuos no atendimento aos direitos das crianças.

\section{Direitos das crianças}

Magalhães (1997) apoiou-se na história da educação da infância em Portugal e Soares (1997) nas diversas legislações sobre os direitos das crianças em Portugal, fornecendo distintas e importantes ponderações a respeito dos direitos das crianças naquele contexto. Suas reflexões permitiram aproximações com as condições sociais das crianças no Brasil, ao entendermos que as crianças de lá e de cá são crianças, seres para os quais os focos de atenção se voltam e despertam interesses de estudiosos de diversas áreas.

No século XIX, como o contributo das diversas ciências que se começaram a organizar na altura, tais como a pedagogia, a psicologia, a medicina infantil, foi possível marcar claramente a separação das crianças relativamente aos adultos, como uma categoria social especialmente vulnerável com necessidades de proteção (SOARES, 1997, p.78). 
No século XX, Soares mencionou que as novas tendências passaram a ter diferentes significados. Isso ocorreu por meio de uma consciencialização de que as crianças eram fontes humanas essenciais "de cuja dimensão maturacional iria depender o futuro da sociedade" (SOARES, 1997, p. 78).

Diversos foram os exemplos trazidos por Soares sobre a construção e/ou o reafirmamento dos direitos das crianças, a exemplo da $1^{a}$ Declaração dos Direitos da Criança - Declaração de Genebra de 1923; Fundo das Nações Unidas para a Infância - UNICEF, de 1946, criada após a II Guerra Mundial com o objetivo de melhorar a vida das crianças; Declaração Universal dos Direitos da Criança, de 1959; Convenção dos Direitos da Criança, uma iniciativa do governo Polaco de 1979, consubstanciada em fins de 1989, na qual a "Convenção apresenta-se como o ponto de viragem relativamente a anteriores perspectivas para com os direitos da criança. É um documento que reconhece a individualidade de cada criança, sendo salvaguardada quer a sua proteção, quer a sua liberdade" (SOARES, 1997, p. 81).

Sobre os diversos artigos da Convenção reforçamos as ponderações de Soares (1997, p. 82): o Direito à Provisão (reconhecimento dos direitos sociais das crianças - saúde, educação, segurança social, cuidados físicos, vida familiar e cultura); o Direito à Proteção (identificação dos direitos das crianças - ser protegida contra discriminação, abuso físico e sexual, exploração, injustiça e conflito) e o Direito à Participação (identificação dos direitos civis e políticos, liberdade de expressão, acesso à informação e outros).

Apesar de a constituição desses direitos, assumimos uma crítica: o distanciamento daquilo que estabelece a identificação e/ou o reconhecimento dos direitos das crianças frente à falta de conscientização ou vontade política dos legisladores em promulgarem leis que articulem o texto da Convenção a suas realidades.

Em Portugal, a aplicabilidade da Convenção dos Direitos da Criança foi debatida, mas necessariamente não houve uma readequação profunda, haja vista que o país apresentava avanços em relação a outros documentos anteriormente publicados. Em 1995, foirealizada uma avaliação do Relatório apresentado por Portugal ao Comitédos Direitos da Criança. Nesse relatório, 
a adequabilidade dos princípios da Convenção ao quadro legislativo foi valorizada, porém o mesmo relatório apontou a falta de informações suficientes para a aplicação das disposições da Convenção naquele País.

Ao mencionar apontamentos do relatório recebido por Portugal, Soares avaliou que "[...] o Relatório mostra preocupações relativamente a aspectos, que, em sua opinião não assumem ainda um caráter de propriedade no nosso país, e que apresentam, pela sua própria natureza, grandes potencialidades de constituir risco para as crianças envolvidas" (SOARES, 1997, p. 93). Entre os fatores agravantes, Soares assinalou ausência de políticas públicas preventivas relacionadas aos maus tratos das crianças. Sobre esses aspectos a realidade portuguesa se aproximou das condições nas quais crianças de outros países se encontram. No Brasil, por exemplo, os maus tratos às crianças ainda é um dos maiores desafios no cenário contemporâneo, o que nos leva a ponderar a vulnerabilidade a qual estão sujeitas as crianças:

Nenhuma sociedade poderá advogar que faz o melhor pela criança se não a aceitar como pessoa, se não lhe atribuir um estatuto socialmente reconhecido. Mas fazer isso não é equivalente a tratá-la como adulto. As crianças são pequenas e vulneráveis e, devido a tal, precisam de consideração e serviços especiais, diferentes dos adultos.

Será precisamente a atenção dada à vulnerabilidade da criança que permitirá delinear um conjunto de direitos que possam dar resposta cabal às suas necessidades (SOARES, 1997, p. 95).

A vulnerabilidade mencionada no excerto está relacionada a duas facetas. Uma é, como tratou Soares (1997), a vulnerabilidade inerente, ou seja, o fato de as crianças serem fisicamente fracas, dependentes, imaturas, possuírem experiências e/ou conhecimentos limitados e isso as colocam em situação de dependência dos adultos. A outra é a vulnerabilidade estrutural, ou seja, a falta de poder econômico e político, além da ausência de direitos civis das crianças.

Os diferentes documentos que desde o início do século têm vindo a ser elaborados, no sentido de providenciar à criança um conjunto progressivamente mais alargado de direitos, são o resultado, por um 
lado, da crescente valorização que a infância tem vindo a assumir, e, por outro lado, do reconhecimento de necessidades e respostas cada vez mais substantivas para essa categoria social (SOARES, 1997, p. 109).

Ao consideramos como verdade que a infância possa assumir a cena em uma crescente valorização com a intensificação de pesquisas e estudos, o mesmo não se pode dizer das agendas políticas, econômicas e sociais nas quais a infância ainda é marginalizada. Nessa compreensão, muito há que ser feito ainda. Nesse rol de vácuos, Soares defendeu o questionamento necessário "acerca da importância relativa que as sucessivas iniciativas em estabelecer documentos definidores de direitos, mais ou menos abrangentes, quer quantitativa, quer qualitativamente, para a criança poderão ter" (SOARES, 1997, p.110).

Ressaltamos que as mudanças necessárias para afirmar os direitos das crianças não podem ser setorizadas ou fragmentadas. Parece-nos haver questões culturais a serem resolvidas. Um exemplo é a permanência de concepções nas quais a criança sempre é vista pelas suas fragilidades e/ou pelas suas incompletudes.

Outro detalhe interessante é percebermos que ao ocupar as diversas agendas públicas em debates não parece haver a segurança de que essa categoria social ${ }^{2}$, a infância, tem ou terá suas prioridades atendidas. Não desprezamos, contudo, iniciativas legislativas progressistas tampouco as necessidades de mudanças das mentalidades e dos valores, cabem-nos perceber as crianças como seres capazes de agir no mundo, capazes de produzir cultura e que tem muito a ensinar aos adultos.

\section{Educação para a infância, breve histórico}

Destacamos a escolarização da infância, seja por via dos direitos instituídos ou até mesmo pelas necessidades de preparar as crianças para o mundo e para a cultura. Sobre a história da educação da infância em Portugal,

\footnotetext{
2 "A infância enquanto categoria social não se limita aos aspectos biológicos, e não se vincula às definições advindas especificamente das instituições escola e família; é, por assim dizer, um entrelaçamento destas com as diversas redes de bens culturais e/ou simbólicos que também circulam pelas mídias" (BARROS, 2008, p. 56).
} 
Magalhães mencionou que a partir do século XIX, em consequência das revoluções industriais, do urbanismo, da atuação da mulher fora do lar, além de estudos sobre o período etário inferior aos seis anos, essa educação se desenvolveu nos planos teórico e prático.

Instituída a infância escolarizável, a partir dos seis/sete anos, é no decurso do século XIX, que não apenas por consequência das revoluções industriais, do urbanismo e de uma progressiva ocupação da mulher fora do lar, mas também como consequência dos estudos sistemáticos sobre os períodos etários inferiores aos seis anos que se desenvolve extraordinariamente, nos planos teórico e prático, a educação da infância. Em concomitância com estas circunstância históricas, a universalização da instrução básica e sua crescente afirmação como via para a racionalidade, estimulam uma préescolarização da infância e o desenvolvimento de estruturas e de programas pedagógicos de antecipação e preparação para o mundo e para a cultura escolar (MAGALHÃES, 1997, p. 120).

Consoante Magalhães, no século XIX se inaugurou a educação da infância fora do lar e ao fazer isso se instituiu a primeira infância, a meninice. A educação passou a ser uma atividade das amas de criação. Contudo, apenas as famílias de nobres e burgueses eram contempladas e ao longo do Antigo Regime essa era uma prática usual. Nesse caso, não se aplicou a educação como um dos direitos sociais instituído, mas de todo modo constituiu uma experiência com a educação fora do lar.

Do século XIX para o XX, diversas foram as mudanças em relação aos direitos das crianças, nas quais "proteger, acolher, alimentar constituíram e constituem, por consequência, a primeira grande intervenção educativa junto à infância. Uma intervenção que aliás em nada contraria os princípios pedagógicos de pensadores como Locke ou Rousseau" (MAGALHÃES, 1997, p. 122). Embora Rousseau tratasse da educação negativa é preciso lembrar que:

tal educação é justamente a da relação da criança com a natureza, onde a proteção e a vigilância são os factores básicos para a preservação da integridade da criança que deve consentaneamente ficar e ser exposta 
o mais possível ao contacto com o mundo natural (MAGALHÃES, 1997, p. 122).

O crescente desenvolvimento da escolarização com a valoração das ações educativas da primeira infância permitiu reforçar duas ideias inovadoras.
a) quanto mais cedo a criança for submetida a planos educativos estruturados e consequentes, mais longe irá no seu desenvolvimento pessoal e social; b) o êxito escolar varia e depende da iniciação e da preparação da criança à entrada para a escola, acreditando-se que quanto mais preparada e inserida estiver à cultura escolar, de melhores capacidades disporá para entender e resolver com êxito os desafios dessa mesma cultura (MAGALHÃES, 1997, p. 122).

Em Portugal, iniciativas de criação de jardins e/ou de escolas para infância não se estabeleceram unicamente por conta do Estado. Muitos países europeus aceitaram e continuam a aceitar propostas domiciliares para a pré-escolarização.

Até fins do século XIX, as primeiras instituições construídas de raiz para a educação da infância, em Portugal, são aplicações da pedagogia de Froebel. Todavia, apesar de uma multiplicidade de projectos, apenas chegaram a funcionar um jardim de infância em Lisboa e outro no Porto. Foram criados, em contrapartida, vários asilos para a infância desvalida, com abertura a outras crianças. Um movimento cuja história terá de ser escrita nos contextos e a partir de fontes locais. O decreto de 24 de Dezembro de 1901 previa a criação de escolas infantis para as crianças dos 4 aos 6 anos, uma educação que permanecerá gratuita e facultativa (MAGALHÃES, 1997, p. 135-136).

A educação assegurada à infância em Portugal pelo poder público é tão recente como no Brasil. Foi a partir dos anos sessenta que as pressões para a ação educativa estatal para a infância se intensificaram. Essa foi uma realidade nas principais cidades no país, ou seja, nos polos com maior concentração populacional. 
Lisboa concentrava a maioria das escolas infantis existentes. Com a Reforma Veiga-Simão foram lançadas as bases de uma divisão de Educação Pré-escolar. Mas foi já no período subsequente ao Movimento de 25 de Abril de 1974 que a educação infantil se expandiu com sistematicidade e critérios científicos (MAGALHÃES, 1997, p. 138).

Educação da infância, a partir desse período, objetivou "proteção, bem-estar e desenvolvimento da criança do nascimento à escolaridade obrigatória" (MAGALHÃES, 1997, p. 138). Isso não evitou, entretanto, que a educação da infância também oscilasse entre iniciativas filantrópicas e escolas com fins lucrativos, privadas ou não.

Muito há para fazer na educação da infância - uma educação que carece de consensos muito alargados ao nível social. É uma área educacional que tem estado verdadeiramente dependente da boa sorte e da preparação das educadoras e dos educadores de infância, verdadeiros instituidores de racionalidades e de práticas educativas, beneficiando de uma grande autonomia pedagógica. Uma autonomia que não pode deixar de integrar uma componente investigativa, fortalecendo o papel dos profissionais de educação como interlocutores fundamentais nas reflexões e decisões de política educativa (MAGALHÃES, 1997, p. 139-140).

De fato, os processos educativos emergiram constituídos de muitas facetas, entre elas a autonomia e o fortalecimento das ações garantidoras de melhores condições de trabalho dos educadores e das educadoras que sopesamos como essencial, uma vez que profissionais da educação desempenham papel fundamental no processo. É a partir dos olhos e das mãos dos adultos que as crianças se evidenciam.

[...] é precisamente em nome do adulto, aos seus olhos e pelas suas mãos que a criança se evidencia. São as suas palavras que a exprimem e definem. E são esses olhos - os dos adultos - nos quais a criança se revê e reconhece, em qual espelho, procurando imagens bonitas de si, recolhendo significados que interpreta e recria, emprestando-lhes novos e originais sentidos. São essas palavras - as dos adultos - que ela faz sua e usa para falar de si e para si e assim se entender melhor (MARTINS, 1997, p. 151). 
A interação adulto/criança é fundamental para o desenvolvimento de processos educativos, pois o universo infantil encontra-se imerso ou cercado por sujeitos diferentes - os adultos. Essa relação produz conhecimentos e saberes. Nessa visão, a infância é um período interessante e propício para a realização de diversas aprendizagens, ou seja,

de facto, se a educação muitas vezes se impõe como espaço privilegiado de problematização e de desafio teórico e epistemológico, ela é também uma atividade socialmente investida de construção humana, de definição da pessoa e de formação do cidadão democrático (MARTINS, 1997, p. 151-152).

\section{Desenvolvimento psicológico: teias da aprendizagem social e da exploração do capital}

Além dos debates sobre os direitos sociais, outra vertente parece importante para discussão que estabelecemos: o desenvolvimento psicológico e interação pessoal para a melhor interação entre adultocriança. Essa discussão não parece apontar para a unicidade de práticas e/ ou teorias necessárias para a melhor relação entre adultos e crianças e "na verdade, no seio da Psicologia, é notável uma diversidade de tendências divergentes que traduz a pluralidade de possibilidades de análise das relações indivíduo-meio" (MARTINS, 1997, p. 153). Mesmo havendo diferentes conceitos, a Psicologia é uma área importante para o auxílio das inter-relações de crianças e adultos, sendo o adulto um interlocutor privilegiado nessa relação.

[...] o papel normalmente atribuído e assumido pelo adulto de interlocutor privilegiado da criança, se tem reflectido acerca do contributo que ele pode prestar, nomeadamente, ao desenvolvimento dos processos de regulação da criança, na criação de competências de planificação e na estruturação da sua consciência. Este trabalho temse desenrolado predominantemente no âmbito da interacção diádica, onde a comunicação se salienta (MARTINS, 1997, p. 186). 
Uma das qualidades da planificação corresponde à capacidade de organizar e de regular o comportamento. Nessa vertente, o adulto e a criança estabelecem uma interlocução capaz de perpassar a planificação. A isso acrescentamos que "a escolarização familiar foi substituída pela escolarização colectiva. A criança passou a deslocar-se à escola frequentada por outras crianças, alargando o seu mundo. A criança socializa-se na família e fora dela" (PEREIRA; NETO, 1997, p. 120).

A infância é de fato um momento rico para a aprendizagem social. A escola sendo o espaço de socialização pode ser atrativa por meio de seu currículo e/ou de diversas atividades que relevam os saberes das crianças e potencializam suas ações e pensamentos. A escola portuguesa enfrentou desafios para ajustar a escola às necessidades reais da sociedade e para contextualizar conteúdos para as crianças.

A escola portuguesa ainda recentemente se caracterizava pelo seu currículo uniforme, nacional, dos tempos hetero-definidos. Referimo-nos a uma escola dependente e controlada centralmente, unidimensional e instrucional, em oposição à escola pluridimensional. Aquela, desajustada das necessidades reais da sociedade, é motivo de contestações e de preocupação. A escola, onde a criança aprende conteúdos desligados entre si e desinseridos das necessidades de aprendizagem reais e personalizadas, provocou reações nos investigadores, que avançaram com hipóteses de solução (PEREIRA; NETO, 1997, p. 223).

É interessante notarmos que o processo de Reforma Educativa, como apontou Pereira e Neto, contemplou diversas pesquisas sobre a situação dos tempos hetero-definidos da escola, incluindo o repensar do currículo da escola bem com outros fatores relevantes para o processo de ensino. Um currículo mais adequado às realidades parece ter contribuído para a permanência das crianças nas escolas evitando o abandono das atividades escolares.

No contexto do abandono das atividades escolares, entendemos que ao deixar a escola para dedicar-se às atividades laborais, a criança é duplamente penalizada. Primeiro por ter sua mão de obra explorada em virtude do processo capitalista instituído. Em segundo lugar, por que perde 
a oportunidade de compartilhar saberes e experiências a partir de suas descobertas pessoais, ou seja, o universo cultural inerente à escola que a ela não foi permitido frequentar.

Em contextos de exclusão social, o abandono da escolaridade obrigatória coincide frequentemente não apenas com a experiência acumulada de insucesso escolar, mas também com fortes pressões para a entrada precoce no mercado de trabalho, através da obtenção de empregos precários, mal remunerados e clandestinos, ligados à situação de sobre exploração de mão-de-obra infantil. No entanto, às crianças e famílias em situação de exclusão, a alternativa muita vezes coloca-se apenas entre a frequência desesperançada de uma escola promotora de insucesso apreendido e a oportunidade precária de ingresso no mundo do trabalho infantil (SARMENTO, 1997, p. 267).

No cerne da questão se colocou a problemática das políticas públicas avaliando o acesso e/ou permanência na escola. Incluímos nessa perspectiva, outros direitos necessários à seguridade da infância para compor nossa análise. $\mathrm{O}$ insucesso escolar integrou-se a outros aspectos igualmente importantes a exemplo da própria estrutura familiar e de acesso a bens culturais. Isto é, "[...] o abandono escolar tem de ser analisado no quadro das relações que se estabelecem no interior do tecido social, as quais condicionam as realidades internas das escolas que os alunos abandonaram" (SARMENTO, 1997, p. 272).

Constatamos ainda que as crianças em situação de exclusão social, independente da localidade onde se encontram, tendem a abandonar a escola. Em muitos casos optam pelo trabalho em diversos setores, seja por imposição dos responsáveis a quem se encontram subjugadas, seja por não conseguirem conciliar trabalho e estudo. Todas possuem algo em comum: são exploradas pelos capitalistas que desrespeitam legislações, correm risco de morte por acidentes de trabalho, cujas condições são quase sempre desumanas. As crianças submetidas a essas terríveis condições se encontram assim desassistidas de qualquer proteção.

No espaço social semirural, a escola tem sido a responsável pela transição dos camponeses à situação de assalariados. Isso ocorreu e ainda 
ocorre muito embora a "formação escolar retira a mão-de-obra infantil ao menos uma parte do dia, do duro trabalho nos campos no interior do contexto doméstico"(SARMENTO, 1997, p. 276). Sarmento complementa que:

Ao mesmo tempo, impõe, pela penetração da escrita e da cultura socialmente considerada como válida, os padrões culturais dominantes da sociedade urbana, contribuindo, assim muito mais do que para assegurar uma igualdade de oportunidades de sucesso social, para socialização dos jovens nos padrões de vida e de consumo da sociedade industrializada. Como consequência, a realização do processo escolar, enquanto se esforça por gerar a crença na possibilidade da mobilidade social ascendente por via da obtenção do diploma escolar, constrói a transformação da população camponesa, cuja cultura tradicional é predominantemente oral, numa população jovem formalmente alfabetizada, incompatibilizada com o ancestral cultivo dos campos, ainda que devedora de algum dos traços culturais e das formas de vida genuinamente rurais, assim orientada para a procura de trabalho assalariado nas fábricas ou nos serviços (SARMENTO, 1997, p. 277).

A escola na perspectiva de sua multiplicidade de funções, por um lado permitiu e permite o partilhar de novas culturas, mas por outro impôs e impõe ritmos, tempos e formas que se perpetuam. A articulação entre educação e trabalho continua bastante problemática, principalmente quando o insucesso escolar induz à saída das crianças da escola para trabalhos domésticos e/ou clandestinos. Importa

dizer que entendemos que o compromisso social de uma pesquisa é tambémapresentarsuas contribuições para que ocampo observadopossa alimentar-sedosdebatesquesuscita, colocandoempermanentediscussão o sentido daquilo que produz (BARROS; PEREIRA, 2009, p. 90).

\section{Considerações}

Pesquisas e estudos realizados pelos investigadores que compuseram o Projecto de Investigação sobre a Infância em Portugal (PiiP) instituem importantes referenciais para interessados em temáticas 
que versam sobre a infância como categoria social. A realidade abordada em Portugal, nos diversos temas, amplia discussões para que outros países, a exemplo do Brasil, ponderem suas ações no lento avanço das políticas públicas sociais destinadas às crianças.

Com foco comum, essas investigações uniram-se no esforço contínuo para ponderar a multiplicidade de formas de infância e de crianças como um fenômeno plural, uma vez que as crianças não agem nem ressignificam o mundo a seu redor igualmente, nem mesmo como os adultos.

Embora tenhamos encontrado diferentes apresentações metodológicas oriundas de áreas distintas, as investigações problematizam o ser criança e suas identidades na escola construídas social, cultural e historicamente. Ainda assim, constatamos que a considerável circulação de temáticas sobre a infância não garante, por si só, que as crianças tenham seus direitos assegurados.

Ressalvamos que muitos desafios existem para novas pesquisas e avaliamos como essenciais políticas públicas constituídas por meio de debates ampliados. Diálogos coletivos e conscientes podem ser a diferença enquanto mediadores e formadores de consciências como base de mudanças sociais frente às posturas que ainda se mantêm na perspectiva de uma ordem social que marginaliza os iletrados e os seres pequeninos.

\section{Referências}

ARIÈS, Philippe. História social da criança e da família. 2 ed. Rio de Janeiro: LTC, 2006.

BARROS, Josemir Almeida. Rádio e educação: de ouvintes a falantes, processos midiáticos com crianças. 2008. 152 f. Dissertação (Mestrado em Educação) - Faculdade de Educação, Universidade do Estado do Rio de Janeiro, Rio de Janeiro, 2008.

; PEREIRA, Rita Marisa Ribes. Programas radiofônicos para crianças: a rádio maluca e a universidade das crianças. In: GOUVÊA; Guaracira; NUNES, Maria Fernanda Rezende (Org.). Crianças, mídias e diálogos. Rio de Janeiro: Rovelle, 2009. p. 73-91. 
FERREIRA, Nilce Vieira Campos; BEGNAMI, Patrícia Santos. Ética e formação de Educadores. In: SCHENKEL, Cladecir Alberto; FERREIRA, Nilce Vieira Campos (Org.). Formação inicial e continuada na educação de Jovens e adultos: diálogos e reflexões. v. 1. Uberaba: IFTM, 2009, p. 45-54.

JOHN, Locke. Ensaio sobre o entendimento Humano. São Paulo: Martins Editora, 2012.

MAGALHÃES, Justino Pereira de. Um contributo para a história da educação da infância em Portugal. In: PINTO, Manuel; SARMENTO, Manuel Jacinto (Org.). As crianças: contextos e identidades. Braga: Bezerra, 1997. p. 115-145.

MARTINS, Paula Cristina. Planificação da atividade e tomada de consciência na criança. In: PINTO, Manuel; SARMENTO, Manuel Jacinto (Org.). As crianças: contextos e identidades. Braga: Bezerra, 1997. p. 149216.

PEREIRA, Beatriz Oliveira; NETO, Carlos. A infância e as práticas lúdicas. In: PINTO, Manuel; SARMENTO, Manuel Jacinto (Org.). As crianças: contextos e identidades. Braga: Bezerra, 1997. p. 219-264.

PINTASSILGO, Joaquim; FREITAS, Marcos Cezar de; MOGARRO, Maria João; et al. (Org.). História da escola em Portugal e no Brasil: circulação e apropriação de modelos culturais. Lisboa: Edições Colibri, 2006.

PINTO, Manuel. A infância como construção social. In: PINTO, Manuel; SARMENTO, Manuel Jacinto (Org.). As crianças: contextos e identidades. Braga: Bezerra, 1997. p. 33-73.

; SARMENTO, Manuel Jacinto (Coord.). Saberes sobre as crianças: para uma bibliografia sobre a infância e as crianças em Portugal (1974-1998). Braga: Bezerra, 1999.

Bezerra, 1997.

. (Org.). As crianças: contextos e identidades. Braga: . As crianças e a infância: definindo conceitos delimitando o campo. In. PINTO, Manuel; SARMENTO, Manuel Jacinto (Org.). As crianças: contextos e identidades. Braga: Bezerra, 1997. p. 9-30. 
POSTAMAN, Neil. O desaparecimento da infância. Rio de Janeiro: Graphia, 1999.

ROUSSEAU, Jean-Jacques. Emilio ou da educação. 4. ed. São Paulo: Martins Editora, 2004.

SARMENTO, Manuel Jacinto; et al. A escola e o trabalho em tempos cruzados. In. PINTO, Manuel; SARMENTO, Manuel Jacinto (Org.). As crianças: contextos e identidades. Braga: Bezerra, 1997. p. 265-293. ; PINTO, Manuel. As crianças e a infância: definindo conceitos delimitando o campo. In: ___ _ _ SARMENTO, Manuel Jacinto (Org.). As crianças: contextos e identidades. Braga: Bezerra, 1997. p. 9-30.

SOARES, Natália Fernandes. Direitos das crianças: utopia ou realidade? In. PINTO, Manuel; SARMENTO, Manuel Jacinto (Org.). As crianças: contextos e identidades. Braga: Bezerra, 1997. p. 76-111.

Data de registro: $13 / 05 / 2013$ Data de aceite: 08/07/2013 